\title{
Corticotropin-Releasing Hormone Increases Tonic but Not Sensory-Evoked Activity of Noradrenergic Locus Coeruleus Neurons in Unanesthetized Rats
}

\author{
Rita J. Valentino ${ }^{1}$ and Stephen L. Foote ${ }^{2}$ \\ 'Department of Pharmacology, George Washington University Medical Center, Washington, DC 20037, and 2Department \\ of Psychiatry, School of Medicine, University of California, San Diego, La Jolla, California 92093
}

These studies were designed to further test the hypothesis that corticotropin-releasing hormone (CRH) is released from axons innervating the noradrenergic neurons of the locus coeruleus (LC) and serves to activate these neurons during stress responses. Specifically, the effects of exogenous CRH on the electrophysiological activity of LC neurons in unanesthetized rats were characterized. Intracerebroventricular (I.C.V.) injection of CRH (0.3-3.0 $\mu \mathrm{g})$ caused a dosedependent increase in LC spontaneous discharge rates that became statistically significant 6-9 min after injection and was still evident 30-40 min later. A 1.0 and $3.0 \mu \mathrm{g}$ amount of CRH caused peak increases of $86 \pm 32 \%$ and $184 \pm 29 \%$ (SEM), respectively. In contrast, neither the lowest dose of CRH $(0.3 \mu \mathrm{g})$ nor a high dose of $\mathrm{Ala}^{14} \mathrm{CRH}(3.0 \mu \mathrm{g})$, an inactive analog of $\mathrm{CRH}$, altered LC spontaneous activity. The effects of CRH administration on sensory-evoked activity of LC neurons were also determined. As previously reported (Foote et al., 1980; Aston-Jones and Bloom, 1981b), the repeated presentation of auditory tone stimuli resulted in a brief enhancement of LC discharge, which was usually followed by a period of relatively decreased activity. Administration of 1.0 or $3.0 \mu \mathrm{g}$ CRH enhanced basal discharge during sensory testing, but discharge rates during the excitatory component of the sensory response were not altered. Quantitative analyses revealed that these doses of CRH produced a statistically significant decrease in the ratio of sensory-evoked to basal discharge rates. Additional analyses of the temporal distribution of discharge activity for individual recording sites during sensory testing demonstrated that 1.0 and $3.0 \mu \mathrm{g} \mathrm{CRH}$ altered relative response magnitudes to a statistically significant extent in 7 of 10 and 5 of 7 cases, respectively, while $0.3 \mu \mathrm{g} \mathrm{CRH}$ and $3.0 \mu \mathrm{g} \mathrm{Ala}{ }^{14} \mathrm{CRH}$ were without effect. The present results are consistent with previous studies of $\mathrm{CRH}$ effects on LC activity in anesthetized rats (Valentino et al., 1983; Valentino and Foote, 1987). However, in unanesthetized animals, $\mathrm{CRH}$ is more potent in increasing tonic activity

\footnotetext{
Received May 15, 1987; revised Aug. 18, 1987; accepted Aug. 26, 1987.

The authors wish to thank Drs. W. Vale and J. Rivier of the Peptide Biology Laboratory, The Salk Institute, for generously providing the peptides used in this study. Additionally, we would like to thank Dana Paris for expert technical assistance, and Thu Hoang for preparation of the manuscript. These studies were supported by PHS Grants MH 40008, DA 03695, and by a grant from the Dystonia Medical Research Foundation.

Correspondence should be addressed to Dr. Rita J. Valentino, Department of Pharmacology, George Washington University, 2300 Eye St., N.W., Washington, DC 20037

Copyright (c) 1988 Society for Neuroscience $0270-6474 / 88 / 031016-10 \$ 02.00 / 0$
}

and does not decrease the absolute magnitude of sensoryevoked activity. The present results support the hypothesis that CRH released from fibers innervating the LC may affect the tonic activity of these cells and the relationship between tonic discharge and phasic, sensory-evoked activity. These electrophyslological effects may constitute one step in an amplification process whereby $\mathrm{CRH}$, acting as a neurotransmitter, alters LC discharge activity, thereby inducing certain components of stress responses.

Substantial evidence indicates that corticotropin-releasing hormone (CRH) transported via the pituitary portal system acts to release pituitary ACTH during stress responses (Vale et al., 1981; Rivier et al., 1982; Plotsky, 1985). Other observations are consistent with the hypothesis that CRH also acts in extrahypophyseal brain pathways as a neurotransmitter to initiate integrated CNS responses to stressful stimuli. For example, CRHlike immunoreactivity has been localized in discrete neuronal circuits in extrahypophyseal regions (Bloom et al., 1982; Bugnon et al., 1982; Merchenthaler et al., 1982; Olschowka et al., 1982; Cummings et al., 1983; Swanson et al., 1983). Likewise, specific CRH binding sites have been demonstrated in many of these same areas (Wynn et al., 1984; DeSouza et al., 1985; DeSouza, 1987). Central administration of CRH in doses sufficient to cause ACTH release results in a variety of behavioral (Britton et al., 1982, 1985; Sutton et al., 1982; Kalin et al., 1983) and autonomic effects (Brown et al., 1982; Fisher et al., 1982; Brown and Fisher, 1985), in addition to the endocrine components of the stress response. Since many of these behavioral and autonomic effects can be elicited in hypophysectomized or adrenalectomized animals, they appear to be mediated by CNS actions of CRH. Finally, CRH alters the electrophysiological activity of certain CNS neurons when applied directly to the cells or after intracerebroventricular (I.C.V.) administration (Aldenhoff et al., 1983; Eberly et al., 1983; Valentino et al., 1983; Siggins et al., 1985; Valentino and Foote, 1987).

The noradrenergic nucleus locus coeruleus (LC) is one area in which CRH immunoreactive fibers have been localized (Bloom et al., 1982; Bugnon et al., 1982; Merchenthaler et al., 1982; Olschowka et al., 1982; Cummings et al., 1983; Swanson et al., 1983). A role for the $\mathrm{LC}$ in stress responses has been suggested by previous studies demonstrating increased norepinephrine turnover in LC terminal areas in rats exposed to stressful noxious stimulation (Thierry et al., 1968; Cassens et al., 1980, 1981) and increased LC neuronal activity in anesthetized rats exposed to physiological stressors (Cedarbaum and Aghajanian, 1978; 
Elam et al., 1981, 1984). Moreover, LC activity in unanesthetized animals has been shown to be elevated during heightened states of arousal and behavioral vigilance (Foote et al., 1980; Aston-Jones and Bloom, 1981a, b), suggesting that increased LC activity may be associated with behavioral responses to stress. The widely divergent efferent pathways originating from the LC (Swanson and Hartman, 1976; also reviewed in Foote et al., 1983) make this a site where alterations of neuronal activity could potentially be amplified throughout the CNS. These anatomical and physiological charactcristics of the LC have led us to test the hypothesis that stressful stimuli activate the LC by initiating $\mathrm{CRH}$ release from fibers localized here. $\mathrm{CRH}$, thus released, could alter electrophysiological activity within the LC and this altered activity, conveyed via its efferent system, could serve to initiate behavioral and/or autonomic components of stress responses (Valentino et al., 1983; Valentino and Foote, 1986). In testing one component of this hypothesis, we demonstrated previously that CRH causes a dose-dependent, structurally specific increase of LC spontaneous discharge rates in anesthetized rats after I.C.V. administration or after direct application of $\mathrm{CRH}$ to these neurons via a multibarrel micropipette (Valentino et al., 1983). Additionally, in anesthetized rats, CRH was found to attenuate the responses of LC cells to sciatic nerve stimulation (Valentino and Foote, 1987). Since CRH effects on LC neuronal activity may well be quantitatively or qualitatively altcred by general anesthesia, it is important to determine CRH effects on LC activity in unanesthetized animals. Since LC neurons in unanesthetized animals are responsive to a variety of nonnoxious stimuli, the use of such a preparation also permits the determination of $\mathrm{CRH}$ effects on $\mathrm{LC}$ responses to stimuli that are more physiologic than is electrical stimulation of peripheral nerves. The aims of the present study were (1) to establish a dose-response relationship for CRII effects on tonic LC activity in unanesthetized rats; (2) to determine whether LC activity evoked by auditory stimuli in unanesthetized rats is affected by $\mathrm{CRH}$; and (3) to verify the molecular structural specificity of these effects in an unanesthetized preparation.

\section{Materials and Methods}

Surgery. Male Sprague-Dawley rats $(300-400 \mathrm{gm})$ were anesthetized with a $1 \%$ halothane-air mixture administered through a nose cone and positioned in a stereotaxic instrument using blunt ear bars, with the head oriented at a $15 \%$ angle to the horizontal plane (nose down). The skull was exposed, and a $3.0-\mathrm{mm}$-diameter hole, centered $1.1 \mathrm{~mm}$ lateral to the midline and $3.6 \mathrm{~mm}$ caudal to the lambda suture point, was drilled over the cerebellum in order to approach the LC. Six smaller holes were drilled to accept stainless steel jewelers' screws (1/16 in. diameter). For I.C.V. peptide administration, a $1.0 \mathrm{~mm}$ hole was drilled $1.5 \mathrm{~mm}$ lateral to the midline and $1.0 \mathrm{~mm}$ caudal to the bregma suture point, and a guide cannula was lowered $4.6 \mathrm{~mm}$ from the skull surface towards the lateral ventricle. The dura over the cerebellum was carefully removed using a fine needle and iridectomy scissors.

During surgery, a head-mountable micromanipulator was affixed to the skull for subsequent LC neuronal recordings. Since the micromanipulator could be moved only in the dorsal-ventral dimension, accurate anterior-posterior and medial-lateral placement had to be achieved before the manipulator was fixed in place. This was accomplished by recording through the manipulator-mounted electrodes as the entire assembly was lowered on a trajectory toward the LC. Impulse activity was monitored with an oscilloscope and loudspeaker. LC neurons were tentatively identified during implantation by their spontancous discharge rates $(1-5 \mathrm{~Hz})$ : entirely positive, notched wave form, $2-3 \mathrm{msec}$ duration (in an unfiltered trace), and biphasic excitatory-inhibitory responses to noxious stimuli (tail- or paw-pinch). When LC neurons were encountered, the manipulator was cemented in place, and the electrodes were withdrawn to $1 \mathrm{~mm}$ above the $\mathrm{LC}$. The recording electrodes consisted of 3 stainless-steel wires, $25 \mu \mathrm{m}$ in diameter, cut with iridectomy scissors to expose an uninsulated tip. Within the micromanipulator, these wires were enclosed in a 26-gauge guide tube and extended $4 \mathrm{~mm}$ past the ventral terminus of the guide. The opposite ends of the wires were connected to a high-impedance differential amplifier, which was part of the cable attached to the head during recording. Microelectrode signals were led from this preamplifier to filters and additional amplifiers.

The guide tube in the lateral ventricle was sealed by inserting a dummy cannula. Rats were injected with a broad-spectrum, long-duration antibiotic (Flocillin) immediately following surgery. The electrode assembly, skull screws, and guide cannula were sterilized prior to implantation.

Recording. At least $48 \mathrm{hr}$ of postsurgical recovery elapsed before unancsthctized recordings were begun. Two recording situations were employed. In one, rats were positioned in a cloth harness to which they had previously been habituated. The restraint allowed free head, limb, and tail movements while the animal was suspended from a horizontal rod over a $7 \times 9 \frac{1}{2} \times 7$ in. cage in which the animals were normally housed. Rats acclimated to this restraint for $7 \mathrm{~d}$ for durations increasing from 20 min to $2 \mathrm{hr}$ typically show no signs of struggling. After positioning in the sling, a flexible cable was connected from the head-mounted assembly to a WPI DAM5A amplifier for recording. Most recordings were obtained from sling-restrained rats. In later studies, a swivel device was used to hold the recording cable vertically overhead, while allowing unrestricted movement within the cage. Under these conditions, most animals explored the cage for a few minutes at the beginning of the recording session and then sat quietly in a corner of the cage. LC spontancous discharge rates, discharge in response to sensory stimuli, and the effects of $\mathrm{CRH}$ on these measures were not significantly different $(p \gg 0.05)$ in the 2 types of recording sessions and were combined.

Protocol. When unanesthetized recording was initiated, the wire bundle was slowly advanced until activity characteristic of $L C$ neurons was encountered. Well-isolated action potentials with a signal-to-noise ratio of at least 3 were monitored by a window discriminator throughout recording (see Fig. 2). Neuronal activity was recorded either from an individual LC neuron (16 of 49 recordings) or simultaneously from 2 or 3 LC neurons that had similar magnitudes and could not be discriminated from one another. This activity was observed for at least $10 \mathrm{~min}$ prior to data collection. During the initial stage of data collection, repeated auditory stimuli (50-80 trials; $2000 \mathrm{~Hz} ; 20 \mathrm{msec}$ duration) were presented at a frequency of $0.03 \mathrm{~Hz}$. Poststimulus time histograms (PSTHs) wcrc uscd to analyze LC activity in response to these tone presentations. PSTHs were computed on-line on an Apple II Plus computer (program developed by Klaus Liebold, The Research Institute of the Scripps Clinic). One hundred milliseconds prior to each tone onset, a trigger pulse sent to the computer activated a 2-sec-duration sweep, during which action potential counts were recorded. Thus, PSTHs recorded the cumulative number of action potentials occurring at particular latencies during the block of auditory stimulation.

After this block of auditory stimulus presentations, spontaneous activity was recorded as 5 consecutive $3 \mathrm{~min}$ interspike-interval histograms (ISHs), which were used to determine the rate and pattern of spontaneous unit activity. Following this $15 \mathrm{~min}$ interval of prepeptide spontaneous activity, $\mathrm{CRH}$ or $\mathrm{Ala}^{14} \mathrm{CRH}$ (see doses and volumes below) was injected over a $30 \mathrm{sec}$ period through a cannula that fit through the guide tube and extended $1.0 \mathrm{~mm}$ past its end, into the lateral ventricle. Spontaneous activity was recorded during and after this injection as three 3 min ISHs. A block of auditory stimulus presentations was then repeated, using the same number of sweeps as in the prepeptide PSTH. If activity remained stable and artifact-free, a $3 \mathrm{~min}$ ISH was repeated.

Data analysis. Changes in spontaneous activity were calculated by first determining the mean discharge rate during the $15 \mathrm{~min}$ prior to peptide administration. The rates for each postpeptide ISH were analyzed as a percentage of this mean control rate. These data were subjected to a 1-way ANOVA, and statistical significance for particular comparisons was evaluated using the Dunnett and Neuman-Keuls tests. Spontaneous discharge rate during each block of stimulus presentations was calculated as the rate during the last $500 \mathrm{msec}$ of each $2 \mathrm{sec}$ sweep in the block. Pre- and postpeptide spontaneous discharge rates recorded during PSTHs were compared using Student's $t$ test for matched pairs.

PSTH data were analyzed by several methods to determine whether peptide administration altered the absolute or relative magnitudes of responses to auditory stimuli. Discharge rates before and after CRH injection were compared for 2 components of the PSTH, the excitatory 
Figure 1. Histological localization of a recording site. A $100-\mu \mathrm{m}$-thick coronal section through the LC, stained with neutral red, is shown. The arrow indicates the Prussian blue reaction product formed at the recording site. The dashed line delimits the compact dorsal portion of the LC. $I V$, Fourth ventricle; $M V$, mesencephalic nucleus of the trigeminus. Calibration bar, $100 \mu \mathrm{m}$.

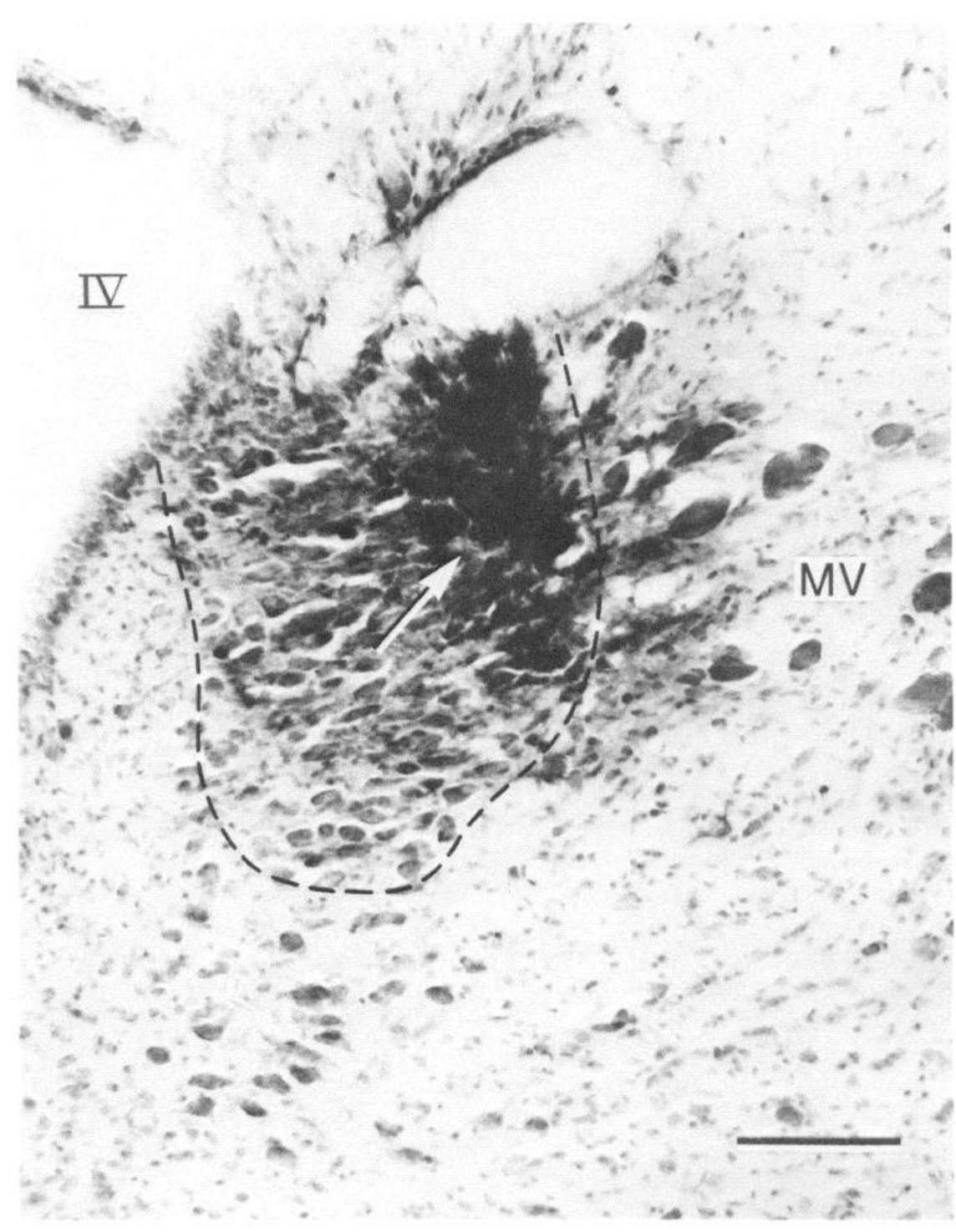

component immediately following the stimulus (stimulus-elicited activity) and the last $500 \mathrm{msec}$ of the PSTH (tonic activity). Additionally, the differences between rates in the 2 components (elicited minus tonic) and the ratio of these rates (elicited/tonic) were compared before and after CRH injection. All comparisons were made using Student's $t$ test for matched pairs. As an additional analysis for individual pairs of preand postpeptide recordings, the histograms were normalized to determine the percentage of total discharges occurring in each bin, and these were plotted as normalized cumulative histograms, which were then compared using the Kolmogorov-Smirnoff test (K-S test; see Fig. 8). In this test the differences between the 2 curves at different time points are compared to a statistical value that is calculated from the total number of discharges in the PSTH (Siegal, 1956).

Histology. After each study, $10 \mu \mathrm{A}$ of cathodal current was passed through the recording electrode for $10-15 \mathrm{sec}$. In addition, $4.0 \mu \mathrm{l}$ of neutral red dye was injected through the ventricular cannula. Animals were anesthetized with pentobarbital and perfused with a $4 \%$ solution of paraformaldehyde in phosphate buffer containing $5 \%$ potassium ferrocyanide to produce a Prussian blue reaction product. Brains were removed and stored for at least $24 \mathrm{hr}$ in this solution, with $15 \%$ sucrose added. The cannula placement was verified by visualization of the dye in the ventricles. Frozen $100 \mu \mathrm{m}$ sections cut on a sliding microtome were mounted on glass-gelatinized slides and stained with neutral red for localization of the electrode tip (see Fig. 1 for an example of this histology).

Peptides. Peptides dissolved in sterile physiological saline were ad- ministered through the I.C.V. cannula over a $30 \mathrm{sec}$ period. CRH was administered in doses of $0.3 \mu \mathrm{g}$ in $0.6 \mu \mathrm{l}, 1.0 \mu \mathrm{g}$ in $2.0 \mu \mathrm{l}$, or $3.0 \mu \mathrm{g}$ in $6.0 \mu \mathrm{l}$. Ala ${ }^{14} \mathrm{CRH}$ was administered as $3.0 \mu \mathrm{g}$ in $6.0 \mu \mathrm{l}$. Only one dose was tested in a given rat on a particular day. Some rats (10) received 3 different treatments (either $0.3,1.0$, or $3.0 \mu \mathrm{g} \mathrm{CRH}$, or $3.0 \mu \mathrm{g} \mathrm{Ala}{ }^{14} \mathrm{CRH}$ ) between the time of implantation and the time the animals were killed. The order of treatments was nonsytematic. However, no treatment was replicated in the same rat. This was because the likelihood of complications, such as losing an implant or movement of the electrode out of the LC, increases with increased duration of the implant. The consequence of these complications is loss of accurate histological verification. Therefore, animals were killed shortly after testing as many doses as possible.

Ovine $\mathrm{CRH}$ and $\mathrm{Ala}{ }^{14} \mathrm{CRH}$ were generously provided by Dr. Jean Rivier of the Peptide Biology Laboratory, The Salk Institute, La Jolla, CA.

\section{Results}

\section{CRH effects on LC spontaneous activity}

Activity was recorded from 21 unanesthetized rats, 17 of which were sling-restrained. An example of raw data and of the ISHs computed is displayed in Figure 2, which shows the $3 \mathrm{~min}$ ISHs generated by activity of an individual neuron before and 6-9 min after $1.0 \mu \mathrm{g} \mathrm{CRH}$. The $\mathrm{CRH}$-induced increase in discharge 

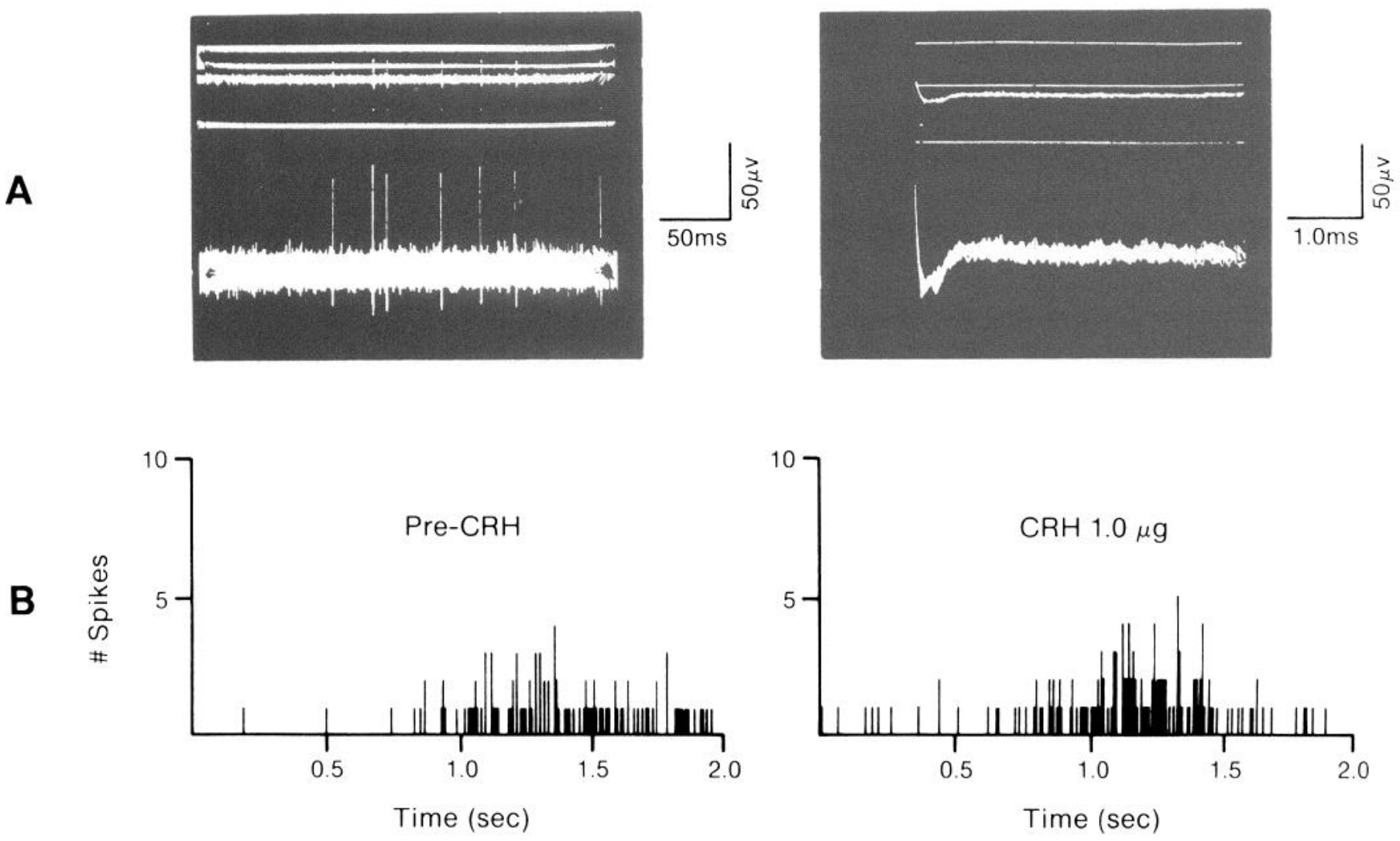

Figure 2. Effect of CRH administration on the activity of an individual LC neuron. $A$, Oscilloscope traces of raw data. The top portion of each trace shows the window that discriminated cellular activity from background. When action potential peaks fell within the window, logic pulses (dots at bottom of upper trace) were relayed to the computer, which generated the ISHs shown in $B$. The left trace displays activity occurring during 5 randomly timed, superimposed sweeps. The right trace displays 10 superimposed sweeps that were triggered by the occurrence of the action potential. Both traces show activity prior to $\mathrm{CRH}$ injection. $B$, Three minute ISHs computed 3 min before (pre-CRH) and 6-9 min after I.C.V. administration of CRH $(1.0 \mu \mathrm{g})$. ISHs display the distribution of interspike intervals, reflecting tonic discharge pattern and rate. The shift toward shorter interspike intervals and the larger number of events after $\mathrm{CRH}$ administration reflect an increase in discharge rate. In this example, discharge rates were $0.67 \mathrm{spikes} / \mathrm{sec}$ (mean interspike interval, $1.49 \mathrm{sec}$ ) and $0.87 \mathrm{spikes} / \mathrm{sec}$ (mean interspike interval, $1.15 \mathrm{sec}$ ) for pre- and post-CRH, respectively. Bin size, $8 \mathrm{msec}$.

rate is reflected in the shift toward shorter interspike intervals in the postinjection ISH. In this example, the mean interspike interval was $1.49 \mathrm{sec}$ prior to, and $1.15 \mathrm{sec}$ following, CRH injection. For the entire time sample, as shown in Figure 3, spontaneous activity was relatively stable during the $15 \mathrm{~min}$ prior to peptide injection. I.C.V. injection of either CRH or Ala ${ }^{14} \mathrm{CRH}$ caused a nonsignificant increase in activity during the $0-3 \mathrm{~min}$ after injection. The lowest dose of CRH $(0.3 \mu \mathrm{g})$ had no significant effect during the 3-6 or 6-9 min interval, while 1.0 and $3.0 \mu \mathrm{g} \mathrm{CRH}$ caused statistically significant, dosedependent increases in LC spontaneous activity at this time (Fig. 3). In contrast, the inactive analog of $\mathrm{CRH}, \mathrm{Ala}^{14} \mathrm{CRH}$, produced a small,nonsignificant decrease in activity during this interval. In order to depict the dose-dependency, variability, and longterm time course of these CRH effects on spontaneous activity, the data for the 6-9 min ISH are replotted in Figure 4, along with data from the PSTH and the second post-CRH ISH. ISH 2 was recorded immediately following the post-CRH auditory stimulus presentations. At this time (34-37 or 49-52 min post$\mathrm{CRH})$, statistically significant increases in LC activity were evident in animals administered either 1.0 or $3.0 \mu \mathrm{g} \mathrm{CRH}$. While all 3 doses of $\mathrm{CRH}$ appeared to produce larger increases in discharge rates during this later ISH, when those rates were compared to rates determined 6-9 min after injection, no significant differences were found by Student's $t$ test for matched pairs.

In some cases, after administration of 1.0 or $3.0 \mu \mathrm{g} \mathrm{CRH}$, behavioral activity of the animal appeared to be enhanced. This was more apparent in sling-restrained rats, where $\mathrm{CRH}$ administration was often accompanied by struggling. Following CRH administration, the 4 freely moving rats exhibited more frequent exploratory movements, such as standing upright on hind legs and changing position in the cage. When these movements interfered with recording quality, data collection was terminated. For this reason, the number of determinations for ISH 2 was smaller than the number for ISH 1.

\section{CRH effects on LC sensory responses}

LC neurons in unanesthetized rats exhibit a characteristic pattern of activity in response to various modalities of sensory stimulation (Foote et al., 1980; Aston-Jones and Bloom, 1981b). The control histograms in Figures 5 and 6 illustrate this response pattern following an auditory stimulus; a brief, poststimulus increase in discharge rate, often followed by a period of suppressed activity. This resembles the response pattern of LC cells in anesthetized rats to a noxious stimulus (Cedarbaum and 
Figure 3. Time course of $\mathrm{CRH}$ activation of $\mathrm{LC}$ spontaneous discharge. The abscissa indicates the time before and after I.C.V. injection of peptide, which occurred at $t=0$. The ordinate indicates the spontaneous discharge rate expressed as a percentage of the mean prepeptide rate. Each point is plotted at the end of the $3 \mathrm{~min}$ interval during which data were accumulated and represents the mean rate of $10,21,8$, and 10 determinations for $0.3,1.0$, and 3.0 $\mu \mathrm{g}$ CRH and $3.0 \mu \mathrm{g} \mathrm{Ala}{ }^{14} \mathrm{CRH}$, respectively. Discharge rates increased nonsignificantly $0-3 \mathrm{~min}$ after peptide injection. While rates fell toward and then below prepeptide values after injection of $\mathrm{Ala}{ }^{14} \mathrm{CRH}$, those for $0.3 \mu \mathrm{g} \mathrm{CRH}$ fell and then rose, and there was a monotonic, dose-dependent increase in rate 3-6 and 6-9 $\mathrm{min}$ after injection of 1.0 and 3.0 $\mu \mathrm{g} \mathrm{CRH}$. Statistical significance was determined by a 1-way ANOVA followed by Dunnett's test. ${ }^{*} p<0.05$; $*^{* *} p<0.01$.

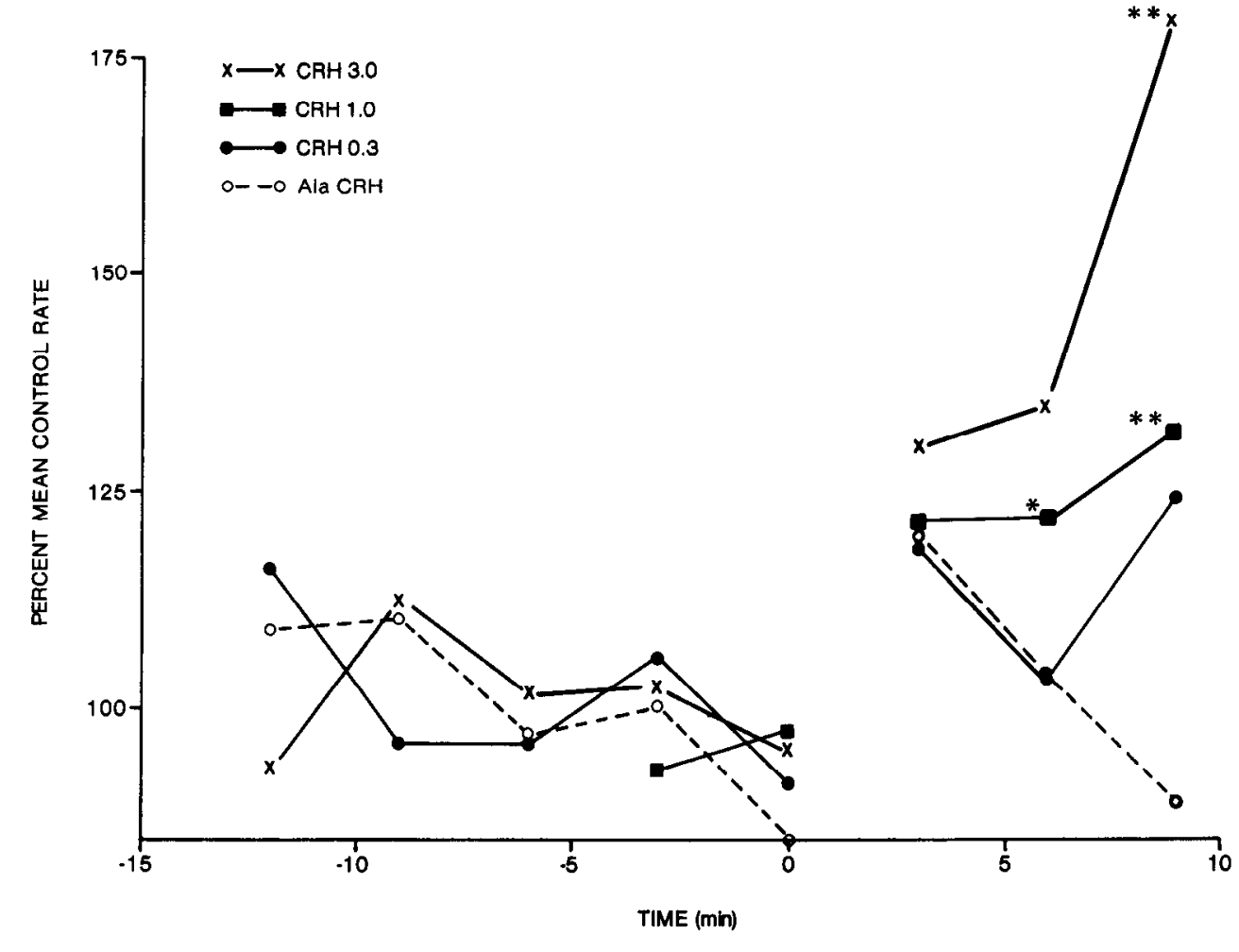

Aghajanian, 1978). CRH effects on sensory-evoked activity were analyzed by comparing pre- and post-CRH PSTHs. Examples of PSTHs computed after 1.0 and $3.0 \mu \mathrm{g} \mathrm{CRH}$ are shown in Figures 5 and 6.

The effects of $\mathrm{CRH}$ on $\mathrm{LC}$ discharge in response to auditory stimuli were quantified by comparing $\mathrm{CRH}$ effects on discharge rates in 2 components of the PSTH, the excitatory response component and a "background," or tonic activity, period. The excitatory response component was delimited by determining the time frame during which poststimulus activity exceeded prestimulus activity by at least 1 standard deviation. Total counts during this period were converted to a counts/sec value, and this was termed "stimulus-elicited activity." Additionally, the total number of counts occurring between 1.5 and $2.0 \mathrm{sec}$ following sweep onset was determined, converted to a counts/sec value, and used as a measure of tonic activity. The mean values for both types of activity for pre- and post-CRH PSTHs for cach dosc arc listed in Table 1.

The absolute magnitudes of stimulus-elicited discharge rates were not significantly altered by any dose of $\mathrm{CRH}$ or by $\mathrm{Ala}^{14} \mathrm{CRH}$

Figure 4. Dose-dependent effect of CRH on LC spontaneous activity. The effect of each dose of $\mathrm{CRH}$ or $\mathrm{Ala}^{14} \mathrm{CRH}(3.0 \mu \mathrm{g})$ is expressed as the percentage increase over the mean prepeptide rate. ISH $I$ is spontaneous activity 6-9 min after peptide injection. $P S T H$ is the mean discharge rate for the last $500 \mathrm{msec}$ of each PSTH during the block of auditory stimulation. $I S H 2$ is the spontaneous discharge rate immediately after the post-CRH PSTH, i.e., 34-37 or 49-52 min after peptide injection. CRH 1.0 and $3.0 \mu \mathrm{g}$ significantly increased LC spontaneous activity 6-9 min after injection, and this effect increased further during ISH 2. Ala ${ }^{14} \mathrm{CRH}$ and CRH $(0.3 \mu \mathrm{g})$ did not significantly alter spontaneous discharge rates. Significance determined by Student's $t$ test for matched pairs. $n$, Number of determinations. Error bars, SEM. 

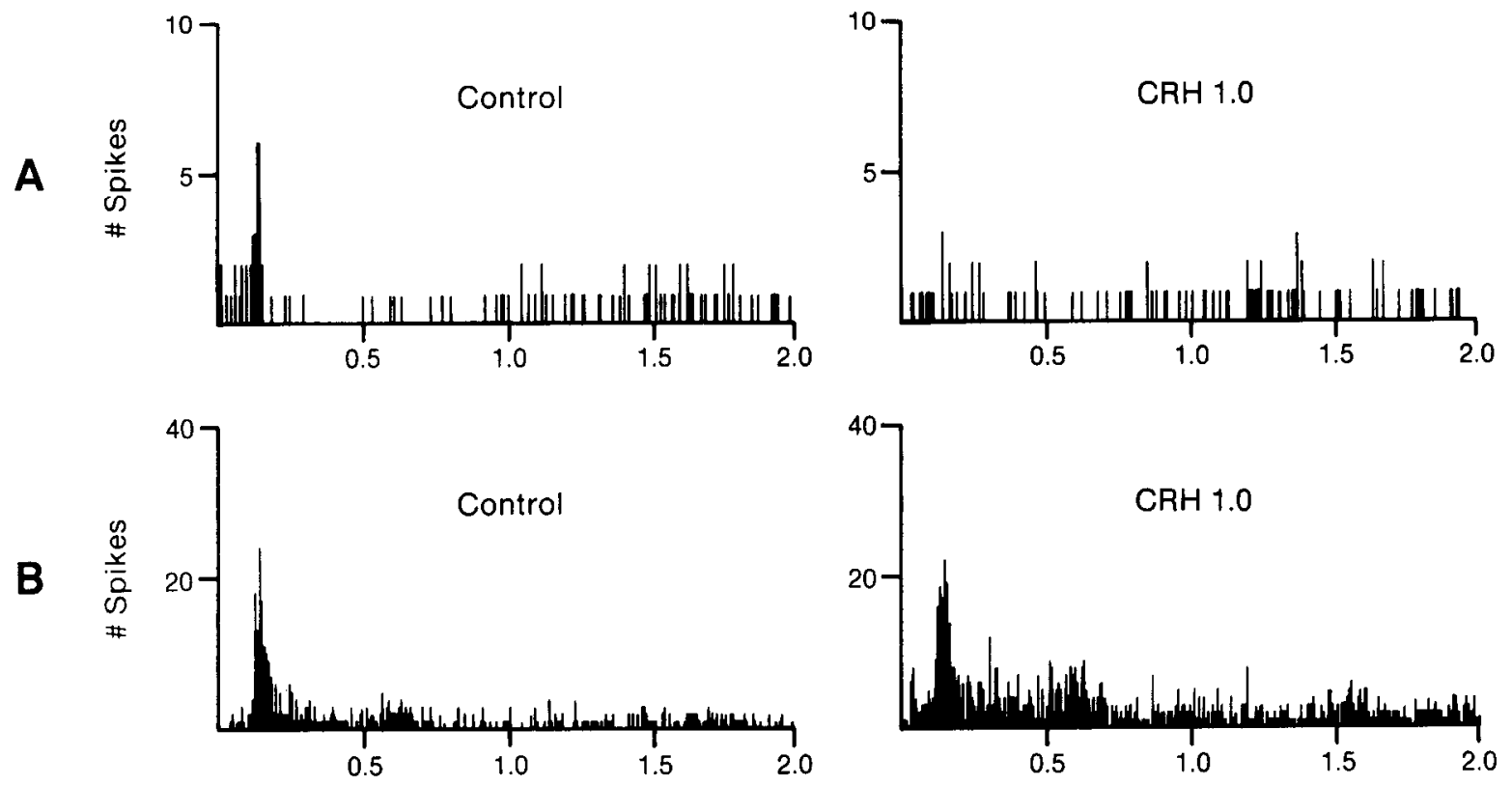

Figure 5. Examples of the effect of CRH $(1.0 \mu \mathrm{g})$ on LC auditory responses. $A$ and $B$ show sample PSTHs computed during the presentation of auditory stimuli beginning $15 \mathrm{~min}$ before and $9 \mathrm{~min}$ after I.C.V. injection of $1.0 \mu \mathrm{g} \mathrm{CRH}$. Each PSTH represents cumulative activity for 50 presentations. A, An example of single-unit activity; the same cell is shown in Figure 3. In this example, CRH decreased sensory-evoked activity and had little effect on tonic activity. $B$, An example in which CRH substantially increased tonic activity but only modestly increased sensoryevoked activity.

(see Table 1). However, further analyscs wcre performed to determine whether tonic and sensory-evoked activity were differentially affected by $\mathrm{CRH}$ administration. Ala ${ }^{14} \mathrm{CRH}$ or the lowest dose of $\mathrm{CRH}(0.3 \mu \mathrm{g})$ caused no significant change in either absolute or relative measures of tonic or stimulus-elicited rates or in the ratio of stimulus-elicited/tonic rates. Although
$\mathrm{CRH}(1.0 \mu \mathrm{g})$ increased tonic discharge rates in 6 of 10 tests during the PSTH interval, the mean increase was not statistically significant $(p>0.05)$. Likewise, the slight increase in stimuluselicited activity after $1.0 \mu \mathrm{g} \mathrm{CRH} \mathrm{did} \mathrm{not} \mathrm{approach} \mathrm{statistical}$ significance $(p \gg 0.05)$. When stimulus-elicited activity is corrected by subtracting tonic rate, the mean control stimulus-
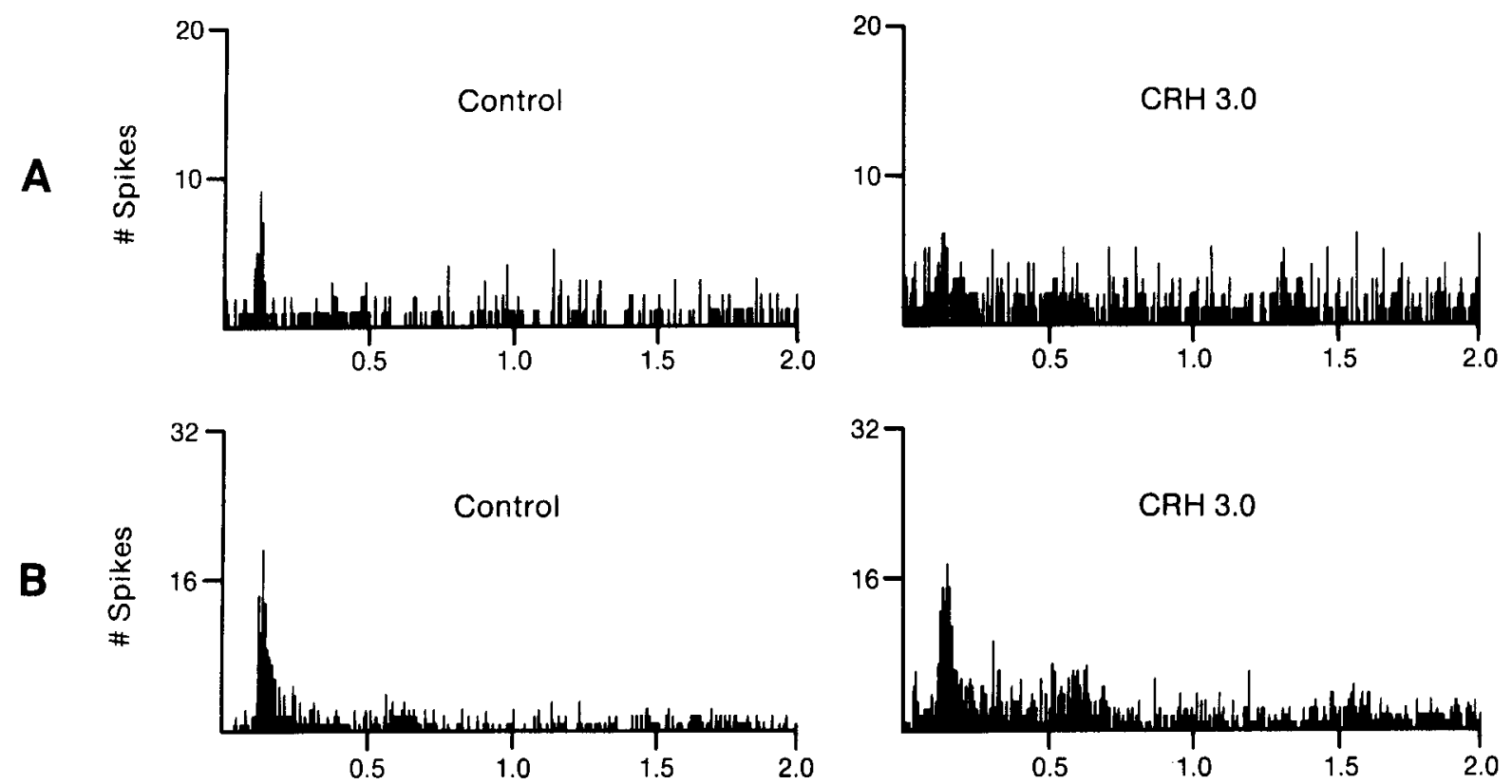

Figure 6. Effects of CRH $(3.0 \mu \mathrm{g})$ on LC auditory response. $A$ and $B$, Sample PSTHs computed during blocks of auditory stimulation beginning $15 \mathrm{~min}$ before and $9 \mathrm{~min}$ after I.C.V. injection of $3.0 \mu \mathrm{g} \mathrm{CRH} . A$ and $B$ show the cumulative activity of 80 and 50 presentations, respectively. In both cases, tonic activity was increased by a larger percentage than was sensory-evoked activity. $A$ is activity recorded from an individual neuron, while $B$ is multiple-neuron activity. Notice the corresponding difference in the scale of the ordinate. 


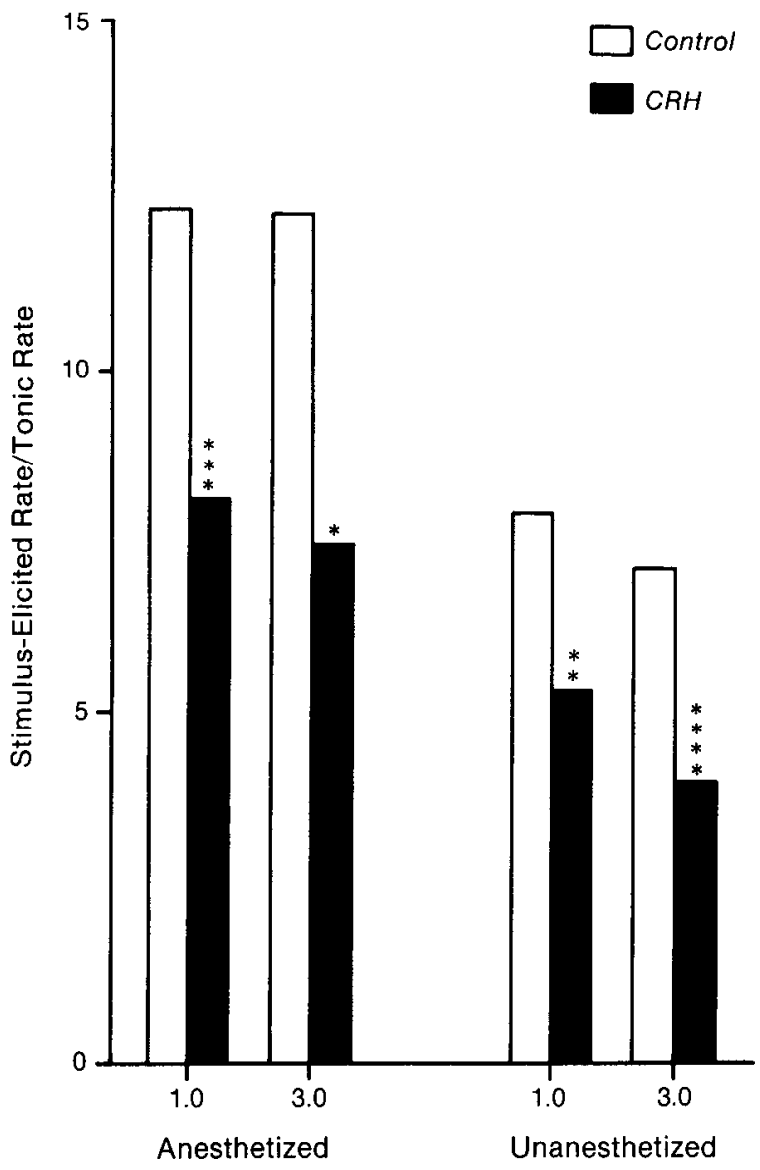

Figure 7. Effects of 1.0 and $3.0 \mu \mathrm{g} \mathrm{CRH}$ on the ratio of sensory-evoked activity to tonic activity in anesthetized and unanesthetized rats. The data from anesthetized rats are from Valentino and Foote (1987). The stimuli were electrical shocks to a rear paw. Ratios of sensory-evoked to tonic activity were computed by the same method used in the present report.

elicited rate $(19.9 \mathrm{~Hz})$ and mean post-CRH-elicited rate $(20.9$ $\mathrm{Hz}$ ) were also not different $(p \gg 0.05)$.

The most consistent effect of CRH $(1.0 \mu \mathrm{g})$ was to decrease the ratio of stimulus-elicited activity to tonic activity (Fig. 7). For example, the ratio of mean stimulus-elicited rate to mean tonic rate decreased from 8.6 in control PSTHs to 4.6 in CRH PSTHs (Table 1). When ratios were computed for individual tests, the mean CRH ratio, 5.3 was significantly less than the control ratio, 7.8 (Fig. $7 ; p<0.025$ ). This decrease in elicited/ tonic rates was evident in 9 of 10 tests at this dose. Thus, although the absolute magnitudes of stimulus-elicited activity were only minimally affected by $1.0 \mu \mathrm{g} \mathrm{CRH}$, they were substantially reduced relative to tonic activity. Moreover, this reduction occurred because increases in tonic activity were relatively greater than increases in stimulus-elicited activity. For example, in this study, tonic activity increased to $223 \%$ of baseline while stimulus-elicited discharge rate increased to only $119 \%$ of baseline.

Similar results were obtained for the 7 tests with $3.0 \mu \mathrm{g} \mathrm{CRH}$. Tonic discharge rates increased in each of 7 determinations, and the mean tonic rate during the PSTH interval was significantly increased by CRH $(p<0.05)$. Stimulus-elicited discharge rates increased in 3 tests and decreased in 4 . The net effect was a small, but not significant, increase in mean elicited discharge rates $(p>0.05)$. Like $1.0 \mu \mathrm{g} \mathrm{CRH}$, the $3.0 \mu \mathrm{g}$ dose decreased the ratio of mean stimulus-elicited discharge to mean tonic rates from $6.7 / 1$ to $3.6 / 1$. This decrease in elicited/tonic rates was evident in all 7 tests at this dose, and the mean ratios for individual tests were as follows: control, 7.1, post-CRH, 4.0 (Fig. $8 ; p<0.001)$. As for the $1.0 \mu \mathrm{g}$ dose, the decrease in elicited/ tonic ratio by $3.0 \mu \mathrm{g}$ CRH reflected the fact that the increase in tonic activity $(238 \%)$ was much greater than the increase in stimulus-elicited activity (127\%). For 1.0 and $3.0 \mu \mathrm{g}$ tests combined, decreased elicited/tonic ratios were evident in 16 of 17 tests.

One additional analysis was performed in order to determine whether the CRH effect of decreasing evoked activity relative to tonic activity in PSTHs could be demonstrated to be statistically significant for individual tests. This was done by first normalizing each PSTH and plotting the cumulative percentage of discharges occurring over time (Fig. $8 \mathrm{C}$ ). The maximum difference between prepeptide and postpeptide normalized cumulative histograms was determined, and if this difference exceeded the K-S statistic (Siegal, 1956), the magnitude of LC sensory responses relative to tonic activity was considered to be significantly altered. Table 1 summarizes the effects of different doses of $\mathrm{CRH}$ and $\mathrm{Ala}{ }^{14} \mathrm{CRH}$ on LC auditory responses, as analyzed by this method. The normalized cumulative PSTHs generated after $3.0 \mu \mathrm{g} \mathrm{CRH}$ were significantly different $(p<$ 0.05 ) from the prepeptide PSTHs in 5 of 7 tests. In each case, the curve was shifted to the right in the presence of CRH (cf., Fig. 8), indicating decreased sensory-evoked activity relative to tonic activity. Significant differences were usually observed between 100 and $400 \mathrm{msec}$ after the onset of the auditory stimulus,

Table 1. CRH effects on $L C$ activity during auditory stimulus presentation

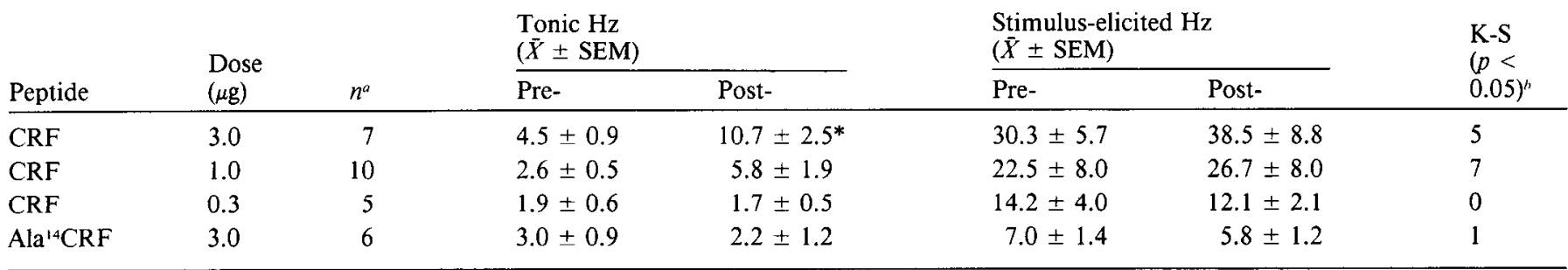

a $n$, Number of determinations (multiple- or single-unit activity). Each determination for the same treatment is a single determination in an individual rat; only one dose was tested on a given day.

"Number of determinations in which the peptide injection produced a significant $(p<0.05)$ change in the normalized cumulative histogram, as determined by the K-S test.

$* p<0.05$. 

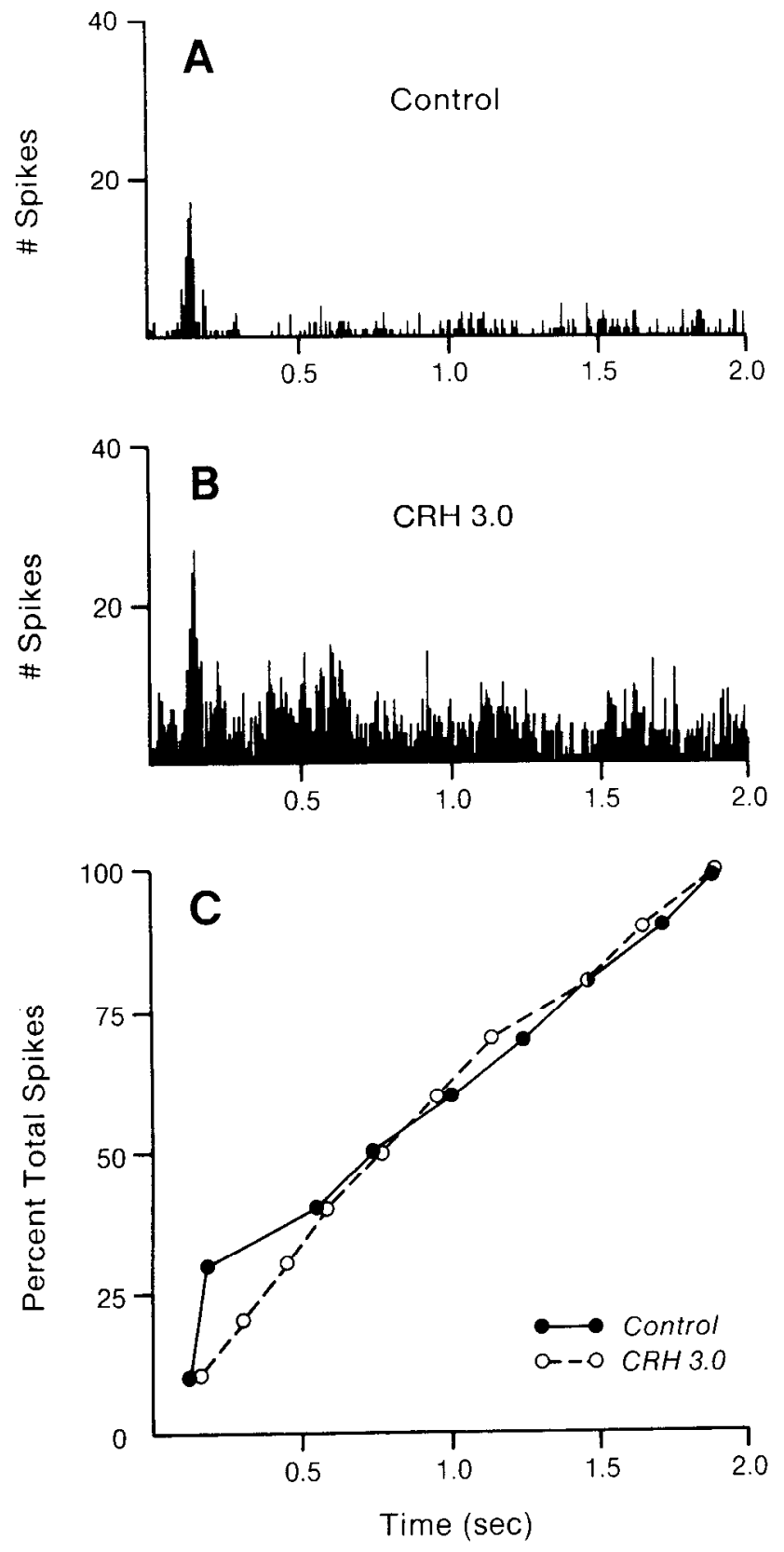

Figure 8. Example of quantification and statistical analysis of $\mathrm{CRH}$ effects on LC auditory responses using the K-S test. $A$ and $B$, PSTHs generated from one recording site before and after administration of $3.0 \mu \mathrm{g} \mathrm{CRH}$. C, Control and CRH histograms replotted as normalized, cumulative distributions of counts. The decreased intensity of the sensory response relative to tonic activity is reflected in the increased linearity (counts more equally distributed among bins) of the distribution following CRH administration. The differences between control and CRH values were determined for 20 time points, and if any of these values exceeded the K-S statistic, the curves were considered significantly different. For this example, the K-S value for $p<0.05$ is 0.088 , and the difference between the 2 curves in the interval between 200 and $440 \mathrm{msec}$ ranges from 0.09 to 0.15 , demonstrating a statistically significant effect.

although in some cases there was still a significant difference in the pattern of sensory response up to $1 \mathrm{sec}$ after the stimulus.

A similar change in the temporal distribution of discharges was produced by $1.0 \mu \mathrm{g} \mathrm{CRH}$ in 7 of 10 tests, with the maximum difference occurring between 60 and $580 \mathrm{msec}$ after the auditory

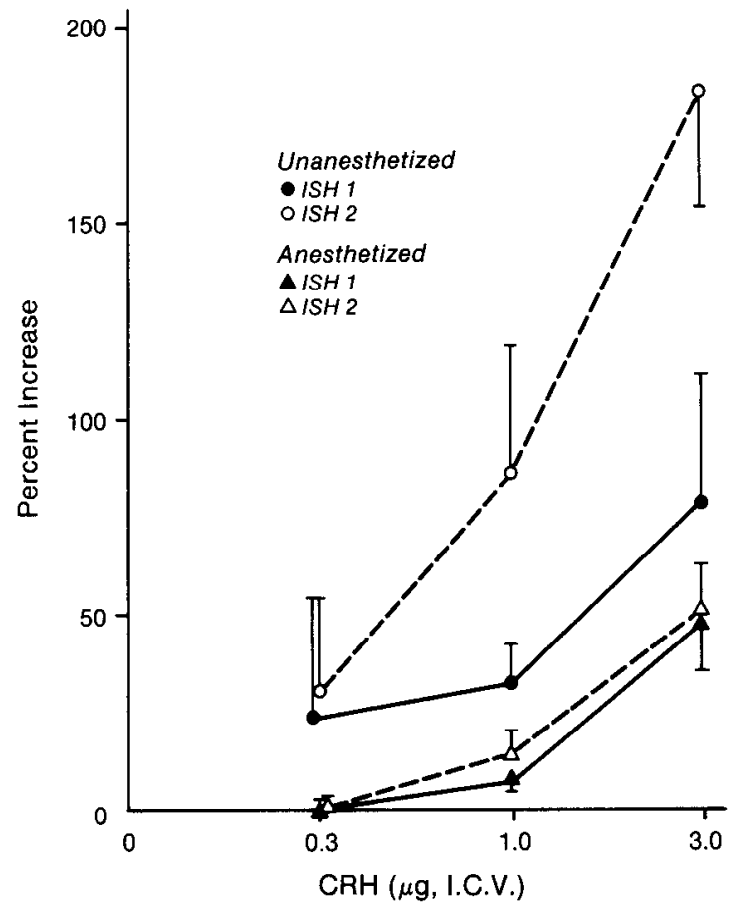

Figure 9. Dose-response relationships for $\mathrm{CRH}$ effects on $\mathrm{LC}$ tonic activity in anesthetized and unanesthetized rats. CRH was administered I.C.V., one dose per rat. For anesthetized rats, each point represents the postinjection spontaneous discharge rate, expressed as a percentage of the mean prepeptide rate, recorded $3 \mathrm{~min}$ after $\mathrm{CRH}$ administration (solid triangles) or immediately after a block of sciatic nerve stimulation (15-19 min after CRH administration; open triangles). For unanesthetized rats, each point represents the postinjection spontaneous discharge rate, expressed as a percentage of the mean prepeptide rate, recorded 9 min after injection (solid circles) or immediately after a block of auditory stimulation (approximatcly $45 \mathrm{~min}$ after injection). Each point is the mean of 4-21 rats. Vertical lines, 1 SEM. The abscissa is on a log scale. $\mathrm{CR} H$ causes greater increases in tonic activity in unanesthetized rats, and these effects are even greater $45 \mathrm{~min}$ after injection. In contrast, CRH effects on LC tonic activity in anesthetized rats appear to peak 3 min after injection (see Valentino and Foote, 1987, for details of studies in anesthetized rats).

stimulus, although in one animal, significant differences were apparent up to $1.1 \mathrm{sec}$ after stimulus onset. The lowest dose of CRH $(0.3 \mu \mathrm{g})$ did not alter the normalized PSTHs in any of 5 tests. Similarly, $\mathrm{Ala}^{14} \mathrm{CRH}$ had a statistically significant effect in only 1 of 6 tests.

\section{Discussion}

The data presented in this report demonstrate that central administration of $\mathrm{CRH}$ in doses that produce endocrine (Vale et al., 1981), behavioral (Britton et al., 1982, 1985; Sutton et al., 1982; Kalin et al., 1983), and autonomic (Brown et al., 1982; Fisher et al., 1982; Brown and Fisher, 1985) components of stress responses increases spontaneous activity of LC neurons in unanesthetized rats, does not increase sensory-evoked activity, and alters the relationship between these 2 types of activity. The molecular specificity and dose-dependence of these effects are demonstrated by the observation that the inactive $\mathrm{CRH}$ analog, $\mathrm{Ala}^{14} \mathrm{CRH}$, and the lowest dose of $\mathrm{CRH}$ had no effects on spontaneous or sensory-evoked LC activity. These results are generally consistent with those reported in halothane-anesthetized rats (Valentino et al., 1983; Valcntino and Footc, 1987). However, certain consistent differences were also evident. 


\section{Anesthesia and $C R H$ effects on $L C$ tonic discharge rates}

Previously, we demonstrated an enhancement of LC spontaneous discharge by $\mathrm{CRH}$ administration in anesthetized rats (Valentino et al., 1983). In the present study, the increases induced by both 1.0 and $3.0 \mu \mathrm{g} \mathrm{CRH}$ were larger, and the duration of these increases was longer than in anesthetized rats (Fig. 9). For example, in anesthetized rats, $1.0 \mu \mathrm{g}$ CRH caused a small (7\%), but significant, increase in LC spontaneous discharge, which was observed at $3 \mathrm{~min}$ after injection and did not increase further at later times. In the present study, larger increases were observed, and these persisted for $30 \mathrm{~min}$ to $1 \mathrm{hr}$ after injection. A similar decrease in sensitivity to CRH in halothane-anesthetized rats has been reported for blood pressure responses (Kurosawa et al., 1986). Few studies have compared the effects of drugs on LC activity in anesthetized versus unanesthetized animals. However, increased sensitivity of tonic discharge rates in the unanesthetized animal might be predicted since tonic LC discharge activity is more labile (Foote et al., 1980; Aston-Jones and Bloom, 1981a, b) under such conditions than in anesthetized rats, in which LC activity is relatively constant (Cedarbaum and Aghajanian, 1978).

Anesthesia and CRH effects on LC sensory-evoked activity

LC cells in anesthetized animals respond only to noxious stimuli, such as footshock (Cedarbaum and Aghajanian, 1978), while cells of unanesthetized rats are responsive to all modalities of sensory stimuli (Foote et al., 1980; Aston-Jones and Bloom, 1981b). The responsiveness of the LC to diverse sensory stimuli supports the hypothesis that the LC is integral to an arousal mechanism and is involved in the maintenance of behavioral vigilance. Because $\mathrm{CRH}$ has been reported to enhance behavioral responses to novel environmental stimuli (Britton et al., 1982), it might be predicted that it would enhance the impact of sensory stimuli on LC neurons. This hypothesis was tested in a previous study in which a noxious stimulus (sciatic nerve stimulation) was presented to halothane-anesthetized rats (Valentino and Foote, 1987), and in the present study, using auditory stimulus presentation to unanesthetized rats. The response pattern to sensory stimuli is similar in both cases and is characterized by increased discharge followed by a period of relatively decreased activity (the postactivation pause). In anesthetized rats, CRH induced a statistically significant reduction in the absolute magnitudes of LC responses to sciatic nerve stimulation by decreasing the number of discharges in the excitatory component and increasing the number of discharges in the postactivation pause (Valentino and Foote, 1987). This attenuation of LC sensory responses was not quantitatively correlated with the magnitude of increases in tonic activity and occurred at a dose that had little effect on spontaneous discharge rates, suggesting that CRH effects on tonic and evoked LC activity have distincl mechanisms (Valentino and Foote, 1987). In contrast, in unanesthetized rats presented with auditory stimuli there was a tendency for $\mathrm{CRH}$ to slightly increase the number of discharges during the excitatory response component and during the postactivation pause, although this was not statistically significant. Thus, the effect of $\mathrm{CRH}$ on the absolute magnitude of the excitatory component of LC sensory responses appears to differ in the 2 studies. Possible explanations for this difference include that (1) the effective intensity of the sensory stimuli used might differ at the level of the LC, and CRH might preferentially reduce the phasic impact of more potent stimuli; (2) CRH might pref- erentially reduce the potency of noxious versus non-noxious stimuli; (3) there might be a complex interaction of anesthesia with tonic or sensory-evoked activity that produces these effects; (4) there may be such a strong enhancement of tonic activity in unanesthetized preparations that this carries over into the "sensory-evoked" portion of the PSTH and obscures any possible reduction in sensory responses induced by CRH; or (5) there may be a "ceiling effect" on LC discharge rates, with maximal rates being higher in unanesthetized animals, so that $\mathrm{CRH}$ can induce increases in sensory-evoked activity. Several types of additional studies will be necessary to discriminate among these alternatives.

In any case, the net effect of CRH on the relative intensity of LC discharge in response to an auditory stimulus in the present study was similar to that observed on nerve-stimulation responses in anesthetized rats, i.e., a decreased signal-to-noise ratio. This occurred even for cells that exhibited enhanced activity in the excitatory response component, since basal discharge rate increased disproportionately. If the intensity of LC sensory responses relative to tonic rates is an effective signal to target areas, disruption of this relationship by $\mathrm{CRH}$ could have important behavioral consequences. For example, one behavioral consequence of this effect might be a persistent high level of arousal that cannot be enhanced further by phasic environmental stimulation.

\section{Conclusion}

The present results further support and refine the hypothesis that $\mathrm{CRH}$, acting as a neurotransmitter or neuromodulator, serves to tonically activate LC neurons in response to stressors. This hypothesis has also received support from studies demonstrating increased $\mathrm{CRH}$ immunoreactivity in LC following acute and chronic stress (Chappell et al., 1986). The present data suggest that LC neurons would react to such CRH input with a substantial, long-lasting increase in tonic discharge rate, accompanied by little or no increase in phasic activity elicited by discrete stimuli. A presumed consequence of such $L C$ activation would be sustained, enhanced release of norepinephrine in those brain regions receiving $\mathrm{LC}$ innervation.

\section{References}

Aldenhoff, J. B., D. L. Gruol, J. Rivier, W. Vale, and G. R. Siggins (1983) Corticotropin-releasing factor decreases postburst hyperpolarizations and excites hippocampal neurons. Science 221: 875-877.

Aston-Jones, G., and F. E. Bloom (1981a) Activity of norepinephrinecontaining locus coeruleus neurons in behaving rats anticipates fluctuations in the sleep-waking cyclc. J. Ncurosci. 1: 876-886.

Aston-Jones, G., and F. E. Bloom (1981b) Norepinephrine-containing neurons in behaving rats exhibit pronounced responses to non-noxious environmental stimuli. J. Neurosci. 1: 887-900.

Bloom, F. E., E. L. F. Battenberg, J. Rivier, and W. Vale (1982) Corticotropin releasing factor (CRF) immunoreactive neurons and fibers in rat hypothalamus. Reg. Peptides $4: 43-48$.

Britton, D. R., G. F. Koob, J. Rivier, and W. Vale (1982) Intraventricular corticotropin releasing factor enhances behavioral effects of novelty. Life Sci. 31: 363-367.

Britton, K., J. Morgan, J. Rivier, W. Vale, and G. Koob (1985) Chlordiazepoxide attenuates CRF-induced response suppression in the conflict test. Psychopharmacology 86: 170-174.

Brown, M. R., and L. A. Fisher (1985) Corticotropin-releasing factor: Effects on the autonomic nervous system and visceral systems. Fed. Proc. 44: 243-248.

Brown, M. R., L. A. Fisher, J. Speiss, C. Rivier, J. Rivier, and W. Vale (1982) Corticotropin-releasing factor: Actions on the sympathetic nervous system and metabolism. Endocrinology 111: 928-931. 
Bugnon, C., D. Fellman, A. Gouge, and J. Cardot (1982) Corticoliberin in rat brain: Immunocytochemical identification and localization of a novel neuroglandular system. Neurosci. Lett. 30: 25-30.

Cassens, G., M. Roffman, A. Kuruc, P. J. Orsulak, and J. J. Schildkraut (1980) Alterations in brain norepinephrine metabolism induced by environmental stimuli previously paired with inescapable shock. Science 209: 1138-1139.

Cassens, G., A. Kuruc, M. Roffman, P. J. Orsulak, and J. J. Schildkraut (1981) Alterations in brain norepinephrine metabolism and behavior induced by environmental stimuli previously paired with inescapable shock. Behav. Brain Res. 2: 387-407.

Cedarbaum, J. M., and G. K. Aghajanian (1978) Activation of locus coeruleus neurons by peripheral stimuli: Modulation by a collateral inhibitory mechanism. Life Sci. 23: 1383-1392.

Chappell, P. B., M. A. Smith, C. D. Kilts, G. Bissette, J. Ritchie, C. Anderson, and C. B. Nemeroff (1986) Alterations in corticotropinreleasing factor-like immunoreactivity in discrete rat brain regions after acute and chronic stress. J. Neurosci. 6: 2908-2914.

Cummings, S., R. Elde, J. Ells, and A. Lendall (1983) Corticotropinreleasing factor immunoreactivity is widely distributed within the central nervous system of the rat: An immunohistochemical study. J. Neurosci. 3: 1355-1368.

DeSouza, E. B. (1987) Corticotropin-releasing factor receptors in the rat central nervous system: Characterization and regional distribution. J. Neurosci. 7: 88-100.

DeSouza, E. B., T. R. Insel, M. H. Perrin, J. Rivier, W. W. Vale, and M. J. Kuhar (1985) Corticotropin-releasing receptors are widely distributed within the rat central nervous system: An autoradiographic study. J. Neurosci. 5: 3189-3203.

Eberly, L. B., C. A. Dudley, and R. L. Moss (1983) Iontophoretic mapping of corticotropin-releasing factor (CRF) sensitive neurons in the rat forebrain. Peptides 4: 837-841.

Elam, M., T. Yao, P. Thoren, and T. H. Svensson (1981) Hypercapnia and hypoxia: Chemoreceptor-mediated control of locus coeruleus neurons and splanchnic, sympathetic nerves. Brain Res. 222: 373381.

Elam, M., T. Yao, T. H. Svensson, and P. Thoren (1984) Regulation of locus coeruleus neurons and splanchnic, sympathetic nerves. Brain Res. 290: 281-287.

Fisher, L. A., J. Rivier, C. Rivier, J. Spiess, W. W. Vale, and M. R. Brown (1982) Corticotropin-releasing factor (CRF): Central effects on mean arterial blood pressure and heart rate in rats. Endocrinology 110: 2222-2224.

Foote, S. L., G. Aston-Jones, and F. E. Bloom (1980) Impulse activity of locus coeruleus neurons in awake rats and monkeys is a function of sensory stimulation and arousal. Proc. Natl. Acad. Sci. USA 77: 3033-3037.

Foote, S. L., F. E. Bloom, and G. Aston-Jones. (1983) Nucleus locus coeruleus: New evidence of anatomical and physiological specificity. Physiol. Rev. 63: 844-914.

Kalin, N. H., S. E. Shelton, G. W. Karemer, and W. T. McKenney (1983) Corticotropin-releasing factor administered intraventricularly to rhesus monkeys. Peptides $4: 217-220$.
Kurosawa, M., A. Sato, R. S. Swenson, and Y. Takahasi (1986) Sympatho-adrenal medullary functions in response to intracerebroventricularly injected corticotropin-releasing factor in anesthetized rats. Brain Res. 367: 250-257.

Merchenthaler, I., M. A. Hynes, S. Vigh, A. V. Schally, and P. Petrusz (1982) Immunocytochemical localization of corticotropin-releasing factor (CRF) in rat brain. Am. J. Anat. 165: 383-396.

Olschowka, J. A., T. L. O'Donahue, G. P. Mueller, and D. M. Jacobowitz (1982) The distribution of corticotropin-releasing factor-like immunoreactive neurons in rat brain. Peptides 3: 995-1015.

Plotsky, P. M. (1985) Hypophysiotropic regulation of adenohypophyseal adrenocorticotropin secretion. Fed. Proc. 344: 207-214.

Rivier, C., J. Rivier, and W. Vale (1982) Inhibition of adrenocorticotropic hormone secretion in the rat by immunoneutralization of corticotropin-releasing factor. Science 218: 377-378.

Siegal, S. (1956) Nonparametric Statistics, McGraw-Hill, New York.

Siggins, G. R., D. L. Gruol, J. Aldenhoff, and Q. Pittman (1985) Electrophysiological actions of corticotropin-releasing factor in the central nervous system. Fed. Proc. 44: 237-242.

Sutton, R. E., G. F. Koob, M. LeMoal, J. Rivier, and W. Vale (1982) Corticotropin-releasing factor produces behavioral activation in rats. Nature 297: 331-333.

Swanson, L. W., and B. K. Hartman (1976) The central adrenergic system. An immunofluorescence study of the location of cell bodies and their efferent connections in the rat using dopamine- $\beta$-hydroxylase as a marker. J. Comp. Neurol. 163: 467-506.

Swanson, L. W., P. E. Sawchenko, J. Rivier, and W. Vale (1983) Organization of ovine corticotropin-releasing factor immunoreactive cells and fibers in the rat brain: An immunohistochemical study. Neuroendocrinology 36: 165-186.

Thierry, A. M., F. Javoy, J. Glowinski, and S. S. Kety (1968) Effects of stress on the metabolism of norepinephrine, dopamine and serotonin in the central nervous system of the rat. Modification of norepinephrine turnover. J. Pharmacol. Exp. Ther. 163: 163-171.

Vale, W., J. Speiss, C. Rivier, and J. Rivier (1981) Characterization of a 41-residue ovine hypothalamic peptide that stimulates secretion of corticotropin and $\beta$-endorphin. Science 213: 1394-1397.

Valentino, R. J., and S. L. Foote (1986) Brain noradrenergic neurons, corticotropin-releasing factor, and stress. In Neural and Endocrine Peptides and Receptors, T. Moody, ed., pp. 101-120, Plenum, New York.

Valentino, R. J., and S. L. Foote (1987) Corticotropin-releasing factor disrupts sensory responses of brain noradrenergic neurons. Neuroendocrinology 45: 28-36.

Valentino, R. J., S. L. Foote, and G. Aston-Jones (1983) Corticotropinreleasing factor activates noradrenergic neurons of the locus coeruleus. Brain Res. 270: 363-367.

Wynn, P. C., R. L. Hauger, M. C. Holmes, M. A. Millan, K. J. Catt, and G. Aguilera (1984) Brain and pituitary receptors for corticotropin-releasing factor: Localization and differential regulation after adrenalectomy. Peptides 5: 1077-1084. 